\title{
Age-period-cohort effects in pre-existing and pregnancy-associated diseases amongst primiparous women
}

\author{
Amy Metcalfe ${ }^{1,2,3^{*}}$, Sofia B. Ahmed ${ }^{3}$ and Kara Nerenberg ${ }^{1,2,3}$
}

\begin{abstract}
Background: The average age at first birth is steadily increasing in developed countries; however, demographic shifts in maternal age at childbearing have not occurred in isolation. While temporal increases in adverse pregnancy outcomes are typically attributed to increases in maternal age, little is known about how maternal health status has changed across maternal age, period of delivery, and birth cohort.

Methods: Natality files were used to identify primiparous women delivering liveborn, singleton infants in the USA in 1989, 1994, 1999, 2004, 2009, and 2014 ( $n=6,857,185)$. Age-period-cohort models using the intrinsic estimator adjusted for temporal trends in smoking and gestational weight gain were used to quantify temporal changes in the rates of pre-existing (chronic hypertension, pre-existing diabetes) and pregnancy-associated (pregnancyassociated hypertension, gestational diabetes, eclampsia) diseases. Log-linear models were used to model the impact of temporal changes on preterm birth, small, and large for gestational age (SGA/LGA) births.

Results: Significant period effects resulted in temporal increases in the rate of chronic hypertension, pregnancyassociated hypertension, and gestational diabetes, and a significant decrease in the rate of eclampsia. These observed period effects were associated with a 10.6\% increase in the rate of SGA and a 7.1\% decrease in LGA. Had the rate of pre-existing and pregnancy-associated diseases remained static over this time period, the rate of preterm birth would have increased by $5.9 \%$, but instead only increased by $4.4 \%$.

Conclusions: Independent of changes in the incidence of pre-existing and pregnancy-associated diseases as women age, the obstetric population is becoming less healthy over time. This is important, as these changes have a direct negative impact on short-term obstetric outcomes and women's long-term health.
\end{abstract}

Keywords: Age-period-cohort analysis, Pregnancy, Pre-eclampsia, Gestational diabetes, Maternal age

\section{Background}

The increased rate of delayed childbearing in developed countries is undisputed. For example, the average age at first birth increased from 24.9 years in 2000 to 26.3 years in 2014 in the USA [1]. This rise in the average age at first birth is

\footnotetext{
* Correspondence: amy.metcalfe@ahs.ca

'Department of Obstetrics and Gynecology, Foothills Medical Centre, University of Calgary, 140329 St NW, Calgary, Alberta T2N 2T9, Canada

${ }^{2}$ Department of Community Health Sciences, University of Calgary, Calgary, Canada
}

Full list of author information is available at the end of the article driven by a decrease in births to women $<20$ years old ( $42 \%$ decrease between 2000 and 2014) and an increase in births to women $\geq 35$ years old ( $23 \%$ increase between 2000 and 2014) [1]. The demographic shift towards delayed childbearing has become a significant public health issue due to the increased risks of adverse pregnancy outcomes at advanced maternal age [2]. The prevailing view is that pregnancies in women of advanced maternal age are more likely to be impacted by a pre-existing chronic disease, resulting in a reduced ability to adapt to the physiological demands of

(c) The Author(s). 2020 Open Access This article is licensed under a Creative Commons Attribution 4.0 International License, which permits use, sharing, adaptation, distribution and reproduction in any medium or format, as long as you give appropriate credit to the original author(s) and the source, provide a link to the Creative Commons licence, and indicate if changes were made. The images or other third party material in this article are included in the article's Creative Commons licence, unless indicated otherwise in a credit line to the material. If material is not included in the article's Creative Commons licence and your intended use is not permitted by statutory regulation or exceeds the permitted use, you will need to obtain permission directly from the copyright holder. To view a copy of this licence, visit http://creativecommons.org/licenses/by/4.0/ The Creative Commons Public Domain Dedication waiver (http://creativecommons.org/publicdomain/zero/1.0/) applies to the data made available in this article, unless otherwise stated in a credit line to the data. 
pregnancy, thus leading to an increased rate of pregnancy complications [3].

However, demographic shifts in maternal age at childbearing have not occurred in isolation. In recent decades, there have been changes in the prevalence of smoking, obesity, and other chronic diseases-all of which contribute to changes in the health status of the obstetric population and independent of the impact of changing patterns of maternal age. Age-period-cohort (APC) analysis is a classic epidemiologic approach to understand how changes in maternal age at delivery (age), population-level demographic changes (period), and early life or generational exposures (cohort) independently influence specific health outcomes $[4,5]$. APC studies on obstetric outcomes have typically focused on racial differences and have not examined the impact of pre-existing or pregnancy-associated diseases on obstetric outcomes. Examining age, period, and cohort effects simultaneously is important as characteristics of older mothers have changed over time. While first births to women over 35 are now a commonplace, in previous decades, pregnancy at this age almost exclusively occurred in multiparous women having their last birth [6]. However, as the average age at first birth steadily increases, the group of primiparous women giving birth at older ages now includes more healthy women than ever before [7]. Conversely, increased use of assisted reproductive technologies now allows less healthy women, in all age groups, to conceive [8].

This study aimed to examine the age, period, and cohort effects in the prevalence of pre-existing disease and the incidence of pregnancy-associated disease in the obstetric population, and to quantify the impact that temporal changes in pre-existing and pregnancy-associated diseases over a 25-year period have had on obstetric outcomes above and beyond the impact of maternal age alone.

\section{Methods}

Data were obtained on primiparous women delivering singleton, liveborn infants without documented congenital anomalies between 24 and 43 completed weeks of gestation according to the clinical estimate of gestational age from the United States National Center for Health Statistics (NCHS) annual natality files from 1989, 1994, 1999, 2004, 2009, to 2014 $(n=6,857,185)$. These data are obtained by the NCHS from the registration offices in all US states via the Vital Statistics Cooperative Program. Some data elements included in the birth certificate are self-reported by the mother (e.g., race, education), while others (e.g., mode of delivery, pregnancy risk factors) are directly reported by the delivery facility. Detailed instructions are provided to both mothers and health care facilities to ensure data are captured in a consistent manner. The NCHS has a robust quality assurance program in place to monitor the accuracy of data included in the birth certificates. Data were extracted on the presence of pre- existing chronic diseases (i.e., chronic hypertension, preexisting diabetes), pregnancy-associated diseases (i.e., pregnancy-associated hypertension, gestational diabetes, and eclampsia), demographic factors (i.e., maternal age, race, educational attainment, marital status, smoking status, and gestational weight gain), and pregnancy outcomes (i.e., preterm birth, small for gestational age (SGA) at the 10th centile [9] and large for gestational age (LGA) at the 90th centile [9]). Data on pre-existing and gestational diabetes were only available following the 2003 revision of the birth certificate as prior to this point they were combined into a single variable. Only women with complete data on all variables were included in this study. As this study relied exclusively on publicly available de-identified data, it was deemed exempt from ethics review by the Conjoint Health Research Ethics Board at the University of Calgary.

\section{Statistical analysis}

Descriptive statistics were used to characterize the population of primiparous women with pre-existing and pregnancy-associated diseases compared to their healthy peers. Chi-square tests for trend were used to examine the crude temporal trends in the prevalence of pre-existing disease and the incidence of pregnancy-associated disease over time. For the APC analysis, we first calculated the unadjusted rates of pre-existing and pregnancy-associated diseases stratified by maternal age at delivery (age), year of delivery (period), and maternal birth cohort (cohort). Due to the lack of linear independence between variables where cohort= period-age, standard regression modelling techniques are not appropriate. As such, an APC model using the intrinsic estimator (IE) was created for each outcome variable [10]. The APC_IE model uses a principal component approach to generate age, period, and cohort coefficients, standard errors, and $95 \%$ confidence intervals that represent the mean change in outcome (e.g., chronic hypertension and gestational diabetes) associated with a particular APC group relative to the mean for all APC groups combined [10]. Models were further adjusted for temporal changes in smoking and gestational weight gain. Data analysis was performed using the APC_IE procedure in Stata SE Version 14. Adjusted model coefficients were used to estimate the probability of each pre-existing and pregnancy-associated disease for each maternal age group, birth cohort, and 5year period of delivery.

To determine the degree to which trends in the prevalence of pre-existing diseases and the incidence of pregnancyassociated diseases influenced the rate of pregnancy outcomes, we used log-linear models to examine rate ratios and rate differences for each outcome in 2004 versus 2014. This time period was chosen as information on pre-existing and gestational diabetes were only available following the 2003 revision of the US birth certificate. Crude models were originally developed including only study year; models were 


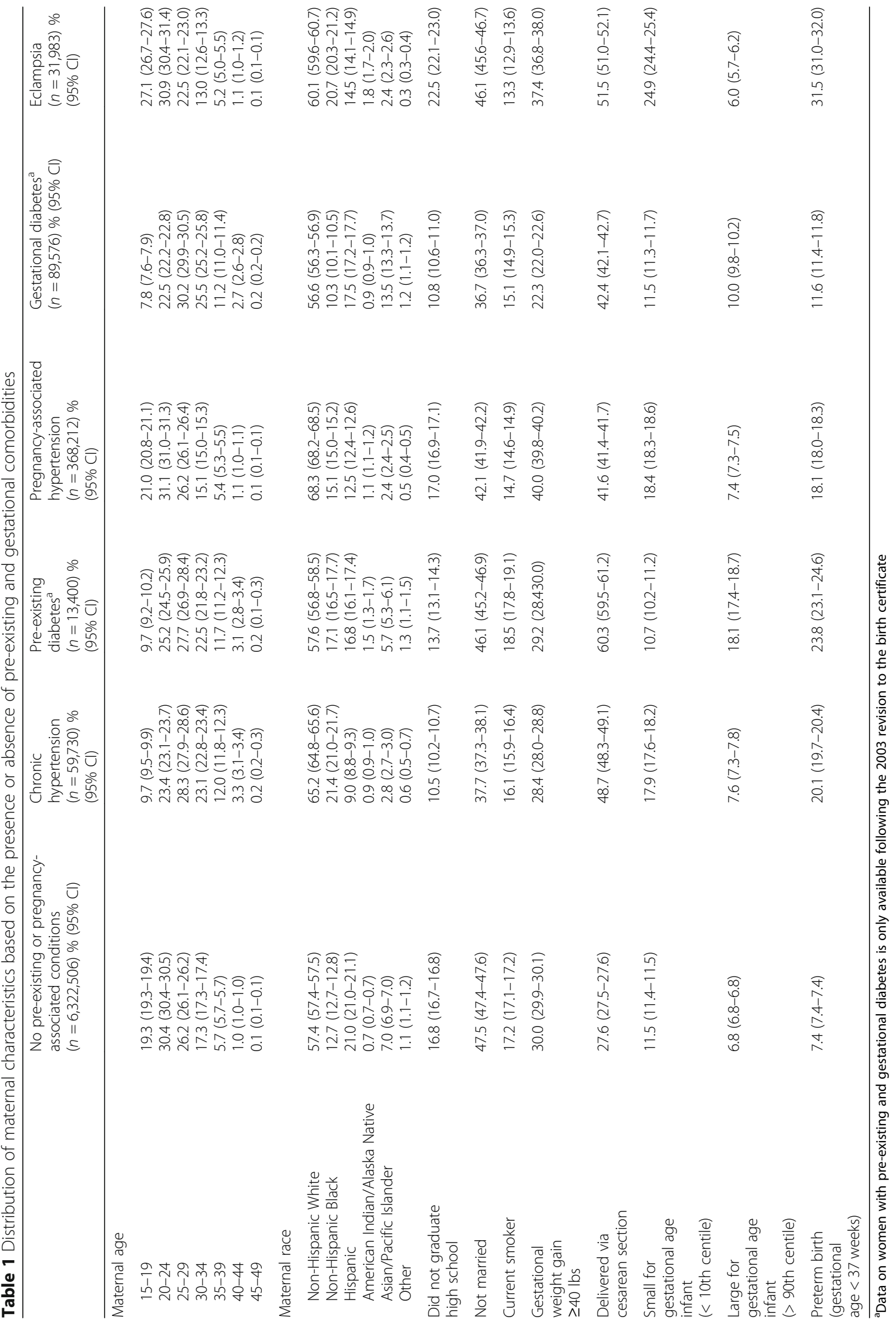


then adjusted for demographic variables and then further adjusted for pre-existing and pregnancy-associated diseases. The difference in the relative rates and percent change was calculated to represent the contribution of temporal changes in the prevalence and incidence of pre-existing and pregnancy-associated diseases on obstetric outcomes between 2004 and 2014 [11, 12]. For all analyses, alpha $<0.05$ was considered statistically significant.

\section{Results}

Maternal characteristics of the primiparous women are outlined in Table 1. With the exception of eclampsia, pregnancy-associated diseases (pregnancy-associated hypertension $5.4 \%$, gestational diabetes $3.8 \%$, eclampsia $0.5 \%$ ) were more common amongst primiparous women than chronic diseases (chronic hypertension $0.9 \%$, pre-existing diabetes $0.6 \%)$. Generally, primiparous women with a pre-existing disease were more likely to be older, married, and have graduated from high school than healthy women (Table 1). The demographic profile of women with pregnancy-associated disease was more heterogeneous. Overall, women with either a pre-existing or pregnancy-associated disease were more likely to deliver preterm or via cesarean section (Table 1).

Significant temporal trends in the prevalence of preexisting disease and the incidence of pregnancy-associated disease were observed over time (Fig. 1). With the exception of eclampsia which had a significant decrease over time $(p<$ 0.001 ), the rate of all other conditions increased over time $(p<0.001)$. As expected, the unadjusted stratified analysis showed strong age effects for all pre-existing and pregnancyassociated diseases, with higher rates being observed in older women (Appendix 1). Of note, crude period effects were also observed. The rate of chronic hypertension, pregnancyassociated hypertension, and gestational diabetes increased over time for all age groups, while the rate of eclampsia decreased over time for all age groups (Appendix 1). For example, 30-34 years old delivering in 2014 (1.67\%, 1.62-1.72) had the same prevalence of chronic hypertension that 35-39 years old had in 1999 (1.68\%, 1.57-1.80). Mixed period effects were observed for pre-existing diabetes, which increased in some age groups (i.e., 15-19 years old) and decreased in others (i.e., 45-49 year olds) (Appendix 1).

Figure 2 and Appendix 2 illustrate the adjusted age, period, and cohort effects on the predicted probability of preexisting and pregnancy-associated diseases. With regards to pre-existing diseases, significant age and period effects were observed for chronic hypertension with significantly higher predicted probabilities in older women and in more recent time periods. No significant trends were observed for preexisting diabetes. With regards to pregnancy-associated diseases, significant age effects were observed in the youngest groups for gestational diabetes, but predicted

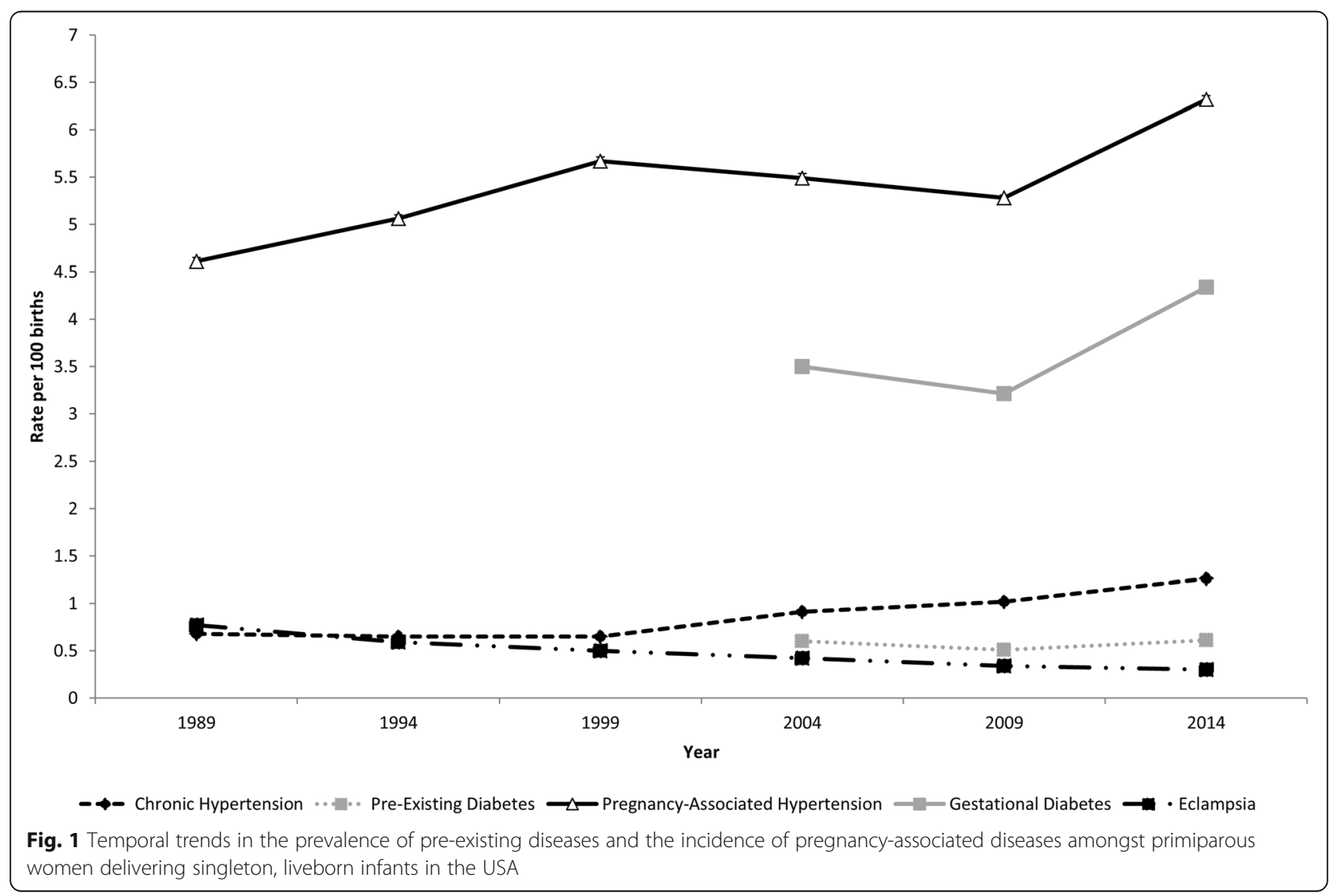




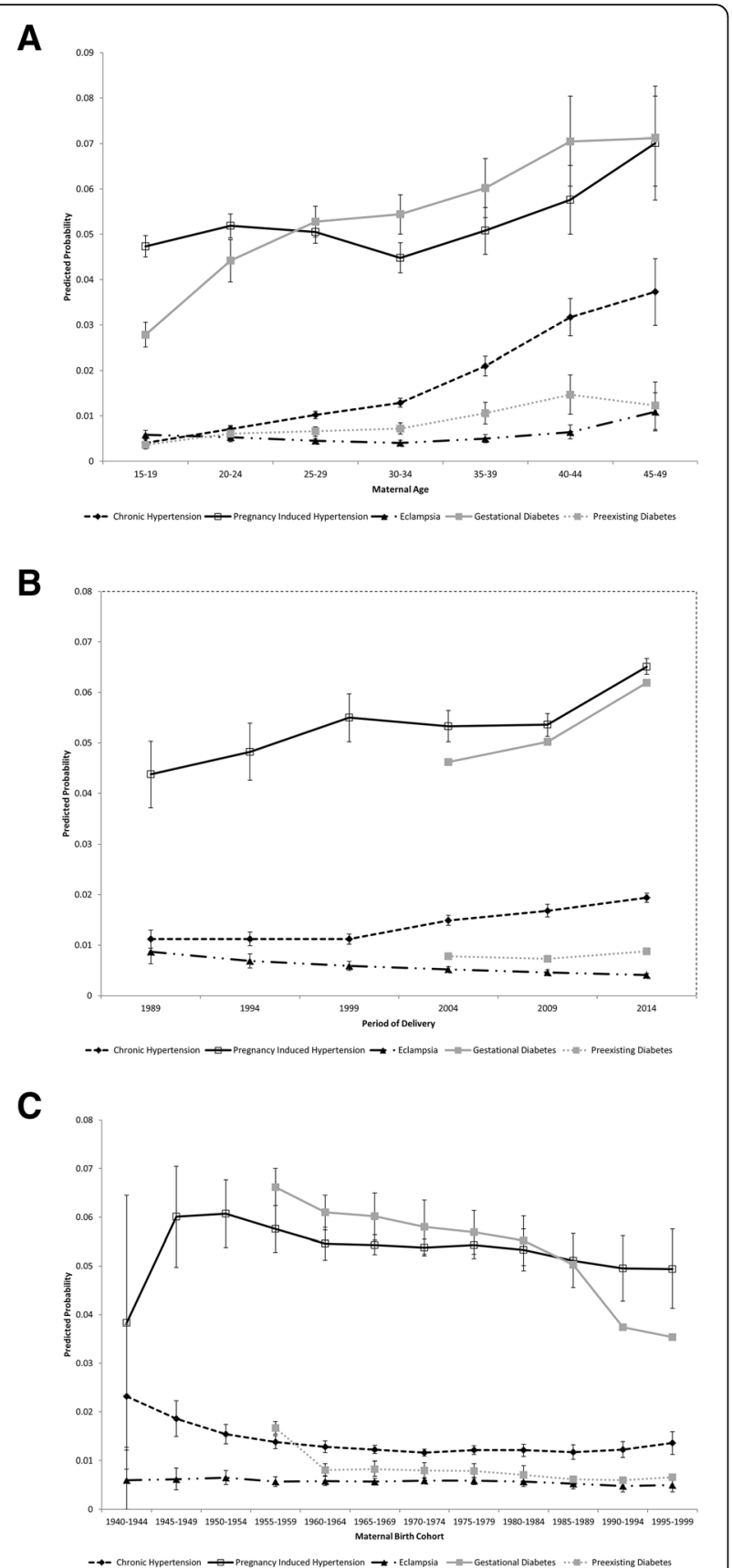

Fig. 2 Predicted probability of pre-existing and pregnancy-associated diseases by a Maternal age group, $\mathbf{b}$ Period of delivery, and $\mathbf{c}$ Maternal birth cohort (based upon age-period-cohort models adjusted for temporal trends in smoking and gestational weight gain) amongst primiparous women delivering singleton, liveborn infants in the USA

probabilities plateaued once women reached their 30s. Significant period effects were observed for all conditions-both pregnancy-associated hypertension and gestational diabetes have significantly higher predicted probabilities in recent time periods-while the predicted probability of eclampsia has decreased significantly over time. No cohort effects were observed for any of the pregnancy-associated diseases studied.

The crude rate of SGA per 1000 births was 113.4 in 2004 and increased to 123.7 in $2014(\mathrm{RR}=1.09,95 \% \mathrm{CI}$ 1.08-1.10) (Table 2). This increase became stronger after adjustment for demographic variables $(\mathrm{RR}=1.13,95 \% \mathrm{CI}$ 1.12-1.4) and further increased after adjustment for preexisting and pregnancy-associated diseases $(R R=1.23$, 95\% CI 1.22-1.25) (Table 2), indicating that the observed period effects in pre-existing and pregnancyassociated diseases are associated with a $10.6 \%$ increase in the rate of SGA. Conversely, the temporal changes in pre-existing and pregnancy-associated diseases are also associated with a $7.1 \%$ decrease in LGA (Table 2).

The crude rate of preterm birth per 1000 births was 86.5 in 2004 and increased to 89.1 in $2014(\mathrm{RR}=1.01,95 \% \mathrm{CI}$ 1.02-1.04) (Table 2). This increase became stronger after the adjustment for demographic variables $(\mathrm{RR}=1.06,95 \% \mathrm{CI}$ 1.05-1.07), but was attenuated after the adjustment for preexisting and pregnancy-associated diseases $(R R=1.04,95 \%$ CI 1.03-1.06). Had the rate of pre-existing and pregnancyassociated diseases remained static over this time period, the rate of preterm birth would have increased by $5.9 \%$, but instead only increased by $4.4 \%$, a reduction of $1.4 \%$.

\section{Discussion}

As anticipated, this study observed higher rates of preexisting and pregnancy-associated diseases in older women; however, period effects were also observed in chronic hypertension, pregnancy-associated hypertension, and gestational diabetes, meaning that not only is the obstetric population getting older, but also women are less healthy over time. By controlling for temporal changes in the underlying obstetric population related to changes in maternal age, gestational weight gain, and smoking status, the temporal trends from the APC analysis more accurately estimate true changes in the incidence and prevalence of these conditions than crude temporal trends which do not reflect other changes that may be occurring in the population simultaneously (e.g., changes in clinical care practices). These matters as a recent Australian study showed that the presence of medical comorbidity is associated with more risk of morbidity and mortality than advanced maternal age itself [13], and our findings demonstrate that these temporal changes in pre-existing and pregnancy-associated diseases are impacting obstetric outcomes at the population level. This is clinically important as even the youngest age groups have an observed increase in the rate of pre-existing and pregnancy-associated diseases. While this study demonstrates the impact of these temporal changes on short-term obstetric outcomes, the increased rate of diseases in these young women may negatively influence their health outcomes as they age.

Our findings are in agreement with other studies examining age-period-cohort effects of pregnancy-associated 
Table 2 Contribution of temporal trends in pre-existing and gestational comorbidities on perinatal outcomes

\begin{tabular}{|c|c|c|c|c|c|}
\hline \multirow[t]{2}{*}{ Perinatal outcome } & \multicolumn{2}{|c|}{ Rate per 100 births } & \multicolumn{3}{|c|}{ Relative change (2004 vs. 2014) } \\
\hline & $\begin{array}{l}2004 \\
(\boldsymbol{n}=1,121,535)\end{array}$ & $\begin{array}{l}2014 \\
(\boldsymbol{n}=1,244,642)\end{array}$ & $\begin{array}{l}\text { Rate difference } \\
(95 \% \mathrm{Cl})\end{array}$ & $\begin{array}{l}\text { Rate ratio } \\
(95 \% \mathrm{Cl})\end{array}$ & $\begin{array}{l}\text { Percent } \\
\text { change }\end{array}$ \\
\hline \multicolumn{6}{|l|}{ Small for gestational age } \\
\hline $\begin{array}{l}\text { Crude } \\
\text { Adjusted for demographic variables }{ }^{a} \\
\text { Adjusted for demographic variables }^{a} \text { and } \\
\text { comorbidities }^{b} \\
\text { Incremental effect of comorbidities }^{b}\end{array}$ & $\begin{array}{l}113.35 \\
110.59 \\
101.26\end{array}$ & $\begin{array}{l}123.65 \\
124.77 \\
124.95\end{array}$ & $\begin{array}{l}10.30(9.48-11.13) \\
14.18(13.36-15.01) \\
23.69(22.88-24.50)\end{array}$ & $\begin{array}{l}1.09(1.08-1.10) \\
1.13(1.12-1.14) \\
1.23(1.22-1.25) \\
0.10(0.10-0.11)\end{array}$ & $\begin{array}{l}9.09 \\
12.83 \\
23.40 \\
10.57\end{array}$ \\
\hline \multicolumn{6}{|l|}{ Large for gestational age } \\
\hline $\begin{array}{l}\text { Crude } \\
\text { Adjusted for demographic variables }{ }^{\mathrm{a}} \\
\text { Adjusted for demographic variables }^{\mathrm{a}} \\
\text { and comorbidities } \\
\text { Incremental effect of comorbidities }^{\mathrm{b}}\end{array}$ & $\begin{array}{l}71.47 \\
72.68 \\
78.74\end{array}$ & $\begin{array}{l}72.02 \\
71.46 \\
71.82\end{array}$ & $\begin{array}{l}0.54(-0.12,1.20) \\
-1.23(-1.89,- \\
0.57) \\
-6.92(-7.60,-6.25)\end{array}$ & $\begin{array}{l}1.01(1.00-1.02) \\
0.98(0.97-0.99) \\
0.91(0.90-0.93) \\
-0.07(-0.07,-0.06)\end{array}$ & $\begin{array}{l}0.76 \\
-1.69 \\
-8.79 \\
-7.10\end{array}$ \\
\hline \multicolumn{6}{|l|}{ Preterm birth } \\
\hline $\begin{array}{l}\text { Crude } \\
\text { Adjusted for demographic variables }{ }^{\mathrm{a}} \\
\text { Adjusted for demographic variables }^{\mathrm{a}} \\
\text { and comorbidities } \\
\text { Incremental effect of comorbidities }^{\mathrm{b}}\end{array}$ & $\begin{array}{l}86.47 \\
83.80 \\
84.72\end{array}$ & $\begin{array}{l}89.06 \\
88.70 \\
88.46\end{array}$ & $\begin{array}{l}2.59(1.87-3.31) \\
4.90(4.18-5.62) \\
3.73(3.02-4.45)\end{array}$ & $\begin{array}{l}1.01(1.02-1.04) \\
1.06(1.05-1.07) \\
1.04(1.03-1.06) \\
-0.02(-0.02,-0.01)\end{array}$ & $\begin{array}{l}2.99 \\
5.85 \\
4.41 \\
-1.44\end{array}$ \\
\hline
\end{tabular}

a Demographic variables include maternal age, maternal race, maternal education, marital status, smoking status, and gestational weight gain

${ }^{\mathrm{b}}$ Comorbidities include chronic hypertension, pregnancy associated hypertension, eclampsia, pre-existing diabetes, and gestational diabetes

diseases and obstetric outcomes. A study examining the APC trends in gestational diabetes in the USA from 1979 to 2010 also observed strong age and period effects in the incidence of gestational diabetes, and concluded that changing trends in the incidence of gestational diabetes were associated with temporal decreases in the incidence of LGA births [12]. Similarly, a study examining APC trends in the incidence of pre-eclampsia in the USA between 1980 and 2010 also observed both age and period effects [4].

Two studies examining APC trends in SGA in the USA between 1975 and 2000 [14] and 1989-2010 [15] both documented declines in SGA births amongst white women, and had contradictory findings amongst black women. Our study found an increasing rate of SGA amongst primiparous women that persisted after adjustment for maternal race. Our study makes a novel contribution by documenting the impact that changing rates of pre-existing and pregnancy-associated diseases has on the incidence of SGA - which may indicate that recent efforts to decrease the incidence of pre-eclampsia through the routine use of lowdose aspirin amongst high-risk women [16], may also be able to prevent the adverse neonatal sequelae associated with this diseases. As the use of aspirin for the prevention of preeclampsia becomes more common in routine clinical practice, it will be important to examine what impact this has on maternal and neonatal outcomes at a population level. Other studies have also reported a temporal decrease in eclampsia rates [17, 18]; a detailed review of medical records for all women with eclampsia in the Netherlands attributed this reduction to more aggressive management strategies for women with hypertensive disorders of pregnancies (i.e., increased use of anti-hypertensive medications, magnesium sulfate, and induction of labor) [17], which may also explain the findings from the current study.

This study has both strengths and limitations. The large sample size permits an investigation of rare exposures and outcomes, while the use of standard natality files with consistent reporting requirements permits an examination of temporal trends. However, this data source lacks important clinical detail on screening and treatment practices. Guidelines for prenatal screening for and treatment of pregnancy-associated diseases have changed over time meaning that our study population comprises both screened and unscreened women and potentially differences in treatments over time [12]. Changes in prenatal screening may partially explain temporal increases in pregnancy-associated diseases [12]. There is also the possibility for residual confounding by unmeasured variables such as body mass index, other health issues, and use of fertility treatments. While the US birth certificate has evolved in recent years to collect data on these important confounders, as data on these variables was not collected in older time periods, we were not able to account for their impact on temporal trends. Additionally, the US birth certificates are known to under-ascertain pre-existing and pregnancyassociated diseases [3]. As this would bias our results towards the null, the true impact of pre-existing and pregnancy-associated diseases on obstetrical outcomes may be even greater than is observed in our study. Finally, while we have attempted to mitigate the impact of changes to the birth certificate by only using variables 
that were consistently defined and reported on both the 1989 and 2003 versions, we cannot rule out the possibility that period effects may reflect reporting changes. However, the consistency of our findings with other studies which used different data sources supports a true period effect.

\section{Perspectives and significance}

While the obstetric risks associated with advanced maternal age are undisputed, this study demonstrates the impact that pre-existing and pregnancy-associated diseases have on obstetric outcomes above and beyond that which can be attributed to the impact of maternal age. Importantly, the prevalence of pre-existing diseases and the incidence of pregnancy-associated diseases are increasing over time amongst primiparous women of all age groups, indicating a need to focus on preventative treatment options to optimize pregnancy outcomes and long-term women's health.

\section{Appendix 1}

Unadjusted rates of pre-existing and pregnancy-associated diseases stratified by maternal age at delivery (age), year of delivery (period), and maternal birth cohort (cohort)

Crude rate of Chronic Hypertension (\%, 95\% CI) by maternal age, maternal birth cohort and year of delivery

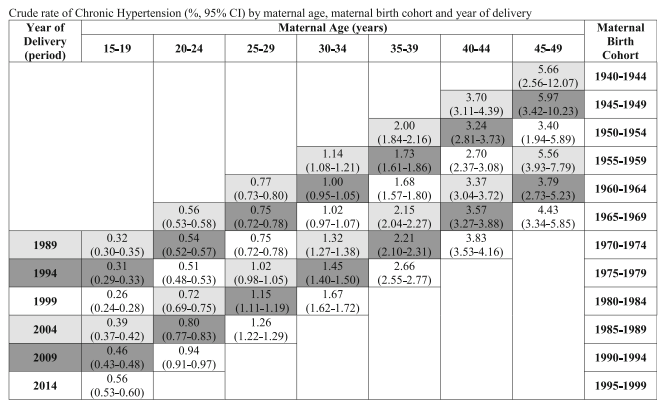

Crude rate of Pre-Existing Diabetes (\%, 95\% CI) by maternal age, maternal birth cohort and year of delivery

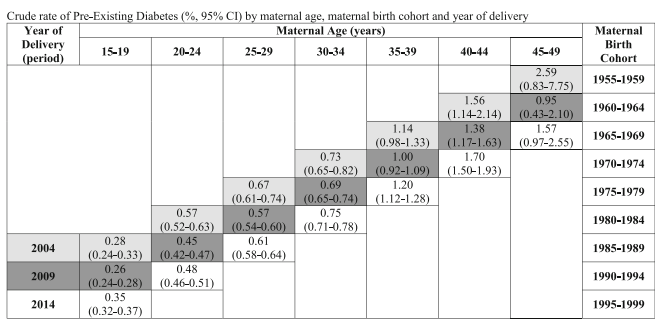

Crude rate of Pregnancy-Induced Hypertension (\%, $95 \%$ CI) by maternal age, maternal birth cohort and year of delivery

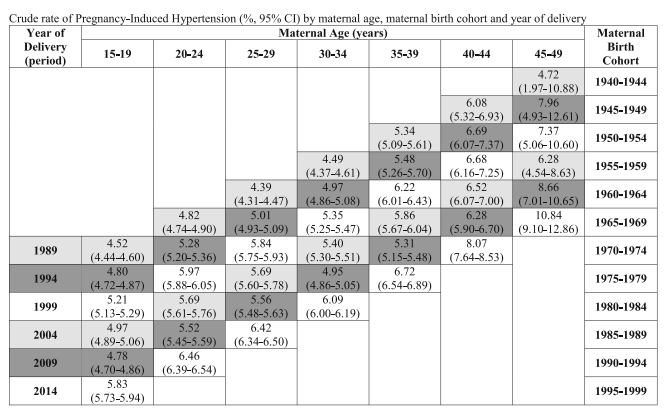

Crude rate of Gestational Diabetes (\%, 95\% CI) by maternal age, maternal birth cohort and year of delivery

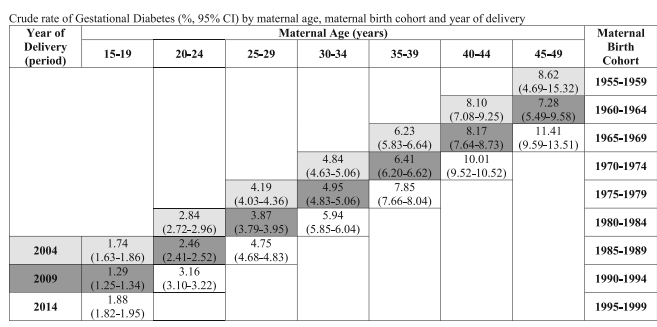

Crude rate of Eclampsia (\%, 95\% CI) by maternal age, maternal birth cohort and year of delivery

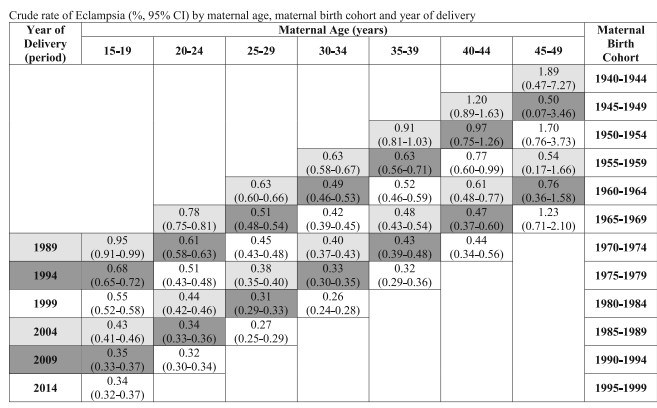

\section{Appendix 2}

Estimated probabilities and 95\% confidence intervals from age-period-cohort models of pre-existing and pregnancy-associated disease amongst primiparous women in the USA delivering liveborn, singleton, nonanomalies infants in 1989, 1994, 1999, 2004, 2009, and $2014(n=6,857,185)$ 


\begin{tabular}{|c|c|c|c|c|c|}
\hline & Chronic hypertension & Pre-existing diabetes & Pregnancy-associated hypertension & Gestational diabetes & Eclampsia \\
\hline \multicolumn{6}{|l|}{ Maternal age } \\
\hline $\begin{array}{l}15-19 \\
20-24 \\
25-29 \\
30-34 \\
35-39 \\
40-44 \\
45-49\end{array}$ & $\begin{array}{l}0.0040(0.0035-0.0044) \\
0.0071(0.0063-0.0079) \\
0.0102(0.0094-0.0110) \\
0.0129(0.0119-0.0139) \\
0.0210(0.0188-0.0231) \\
0.0317(0.0276-0.0358) \\
0.0373(0.0299-0.0446)\end{array}$ & $\begin{array}{l}0.0036(0.0027-0.0049) \\
0.0061(0.0045-0.0077) \\
0.0066(0.0055-0.0076) \\
0.0072(0.0060-0.0085) \\
0.0106(0.0082-0.0130) \\
0.0147(0.0104-0.0190) \\
0.0123(0.0070-0.0175)\end{array}$ & $\begin{array}{l}0.0473(0.0450-0.0497) \\
0.0519(0.0492-0.0545) \\
0.0505(0.0480-0.0531) \\
0.0448(0.0415-0.0481) \\
0.0508(0.0456-0.0559) \\
0.0576(0.0500-0.0652) \\
0.0701(0.0576-0.0826)\end{array}$ & $\begin{array}{l}0.0278(0.0251-0.0306) \\
0.0442(0.0395-0.0488) \\
0.0528(0.0494-0.0562) \\
0.0544(0.0500-0.0587) \\
0.0602(0.0537-0.0667) \\
0.0705(0.0606-0.0804) \\
0.0712(0.0606-0.0804)\end{array}$ & $\begin{array}{l}0.0058(0.0048-0.0068) \\
0.0053(0.0043-0.0062) \\
0.0045(0.0038-0.0050) \\
0.0040(0.0035-0.0046) \\
0.0050(0.0041-0.0059) \\
0.0064(0.0049-0.0080) \\
0.0109(0.0067-0.0151)\end{array}$ \\
\hline \multicolumn{6}{|l|}{ Period } \\
\hline $\begin{array}{l}1989 \\
1994 \\
1999 \\
2004 \\
2009 \\
2014\end{array}$ & $\begin{array}{l}0.0112(0.0094-0.0130) \\
0.0112(0.0099-0.0126) \\
0.0112(0.0102-0.0122) \\
0.0149(0.0139-0.0159) \\
0.0168(0.0156-0.0181) \\
0.0194(0.0185-0.0203)\end{array}$ & $\begin{array}{l}- \\
- \\
- \\
0.0078(0.0060-0.0096) \\
0.0073(0.0057-0.0089) \\
0.0088(0.0078-0.0097)\end{array}$ & $\begin{array}{l}0.0438(0.0372-0.0503) \\
0.0482(0.0426-0.0539) \\
0.0550(0.0502-0.0597) \\
0.0533(0.0502-0.0564) \\
0.0536(0.0513-0.0558) \\
0.0651(0.0636-0.0667)\end{array}$ & $\begin{array}{l}- \\
- \\
- \\
0.0462(0.0411-0.0514) \\
0.0502(0.0454-0.0550) \\
0.0619(0.0590-0.0645)\end{array}$ & $\begin{array}{l}0.0087(0.0063-0.0111) \\
0.0069(0.0055-0.0083) \\
0.0059(0.0050-0.0068) \\
0.0052(0.0046-0.0057) \\
0.0046(0.0040-0.0051) \\
0.0041(0.0037-0.0044)\end{array}$ \\
\hline \multicolumn{6}{|l|}{ Cohort } \\
\hline $\begin{array}{l}1940-1944 \\
1945-1949 \\
1950-1954 \\
1955-1959 \\
1960-1964 \\
1965-1969 \\
1970-1974 \\
1975-1979 \\
1980-1984 \\
1985-1989 \\
1990-1994 \\
1995-1999\end{array}$ & $\begin{array}{l}0.0232(0.0083-0.0380) \\
0.0186(0.0149-0.0223) \\
0.0154(0.0134-0.0174) \\
0.0138(0.0124-0.0151) \\
0.0128(0.0116-0.0140) \\
0.0122(0.0114-0.0131) \\
0.0116(0.0109-0.0123) \\
0.0121(0.0112-0.0130) \\
0.0121(0.0108-0.0133) \\
0.0117(0.0102-0.0132) \\
0.0122(0.0106-0.0139) \\
0.0136(0.0112-0.0159)\end{array}$ & $\begin{array}{l}- \\
- \\
- \\
0.0167(0.0016-0.0319) \\
0.0081(0.0054-0.0109) \\
0.0083(0.0066-0.0100) \\
0.0080(0.0067-0.0093) \\
0.0079(0.0067-0.0092) \\
0.0071(0.0056-0.0087) \\
0.0062(0.0046-0.0078) \\
0.0060(0.0045-0.0075) \\
0.0066(0.0047-0.0085)\end{array}$ & $\begin{array}{l}0.0383(0.0121-0.0645) \\
0.0601(0.0497-0.0705) \\
0.0607(0.0538-0.0677) \\
0.0576(0.0528-0.0624) \\
0.0546(0.0512-0.0579) \\
0.0543(0.0523-0.0564) \\
0.0538(0.0521-0.0555) \\
0.0543(0.0515-0.0571) \\
0.0533(0.0490-0.0576) \\
0.0511(0.0456-0.0567) \\
0.0495(0.0428-0.0562) \\
0.0494(0.0413-0.0576)\end{array}$ & $\begin{array}{l}- \\
- \\
- \\
0.0662(0.0358-0.0967) \\
0.0610(0.0521-0.0700) \\
0.0602(0.0548-0.0656) \\
0.0580(0.0542-0.0618) \\
0.0569(0.0533-0.0604) \\
0.0552(0.0503-0.0600) \\
0.0503(0.0447-0.0558) \\
0.0374(0.0329-0.0419) \\
0.0354(0.0303-0.0405)\end{array}$ & $\begin{array}{l}0.0060(0.0000-0.0127) \\
0.0062(0.0040-0.0085) \\
0.0065(0.0051-0.0080) \\
0.0057(0.0047-0.0067) \\
0.0058(0.0049-0.0068) \\
0.0057(0.0050-0.0064) \\
0.0059(0.0053-0.0065) \\
0.0059(0.0051-0.0066) \\
0.0057(0.0047-0.0067) \\
0.0053(0.0042-0.0064) \\
0.0048(0.0036-0.0059) \\
0.0050(0.0036-0.0065)\end{array}$ \\
\hline
\end{tabular}

All models are adjusted for maternal smoking and gestational weight gain.

\section{Acknowledgements}

Not applicable.

\section{Authors' contributions}

All authors made a substantial contribution to this study. AM conducted the analysis and drafted the manuscript. All authors jointly designed the study, interpreted the findings, critically reviewed the manuscript, and approved the final version.

\section{Funding}

Amy Metcalfe is supported by a new investigator award from the Canadian Institutes of Health Research. Kara Nerenberg is supported by a new investigator award from the Canadian Heart and Stroke Foundation.

\section{Availability of data and materials}

Data are available from the United States National Center for Health Statistics (https://www.cdc.gov/nchs/data_access/vitalstatsonline.htm).

\section{Ethics approval and consent to participate}

As this study relied exclusively on publically available de-identified data, it was considered exempt from ethics review by the Conjoint Health Research Ethics Board at the University of Calgary.

\section{Consent for publication}

Not applicable.

\section{Competing interests}

The authors declare that they have no competing interests.

\section{Author details}

${ }^{1}$ Department of Obstetrics and Gynecology, Foothills Medical Centre, University of Calgary, 140329 St NW, Calgary, Alberta T2N 2T9, Canada. ${ }^{2}$ Department of Community Health Sciences, University of Calgary, Calgary, Canada. ${ }^{3}$ Department of Medicine, University of Calgary, Calgary, Canada.
Received: 20 November 2019 Accepted: 18 March 2020 Published online: 19 April 2020

References

1. Mathews TJ, Hamilton BE. Mean age of mothers is on the rise: United States, 2000-2014. NCHS Data Brief 2016(232):1-8.

2. Klemetti R, Gissler M, Sainio S, Hemminki E. At what age does the risk for adverse maternal and infant outcomes increase? Nationwide register-based study on first births in Finland in 2005-2014. Acta Obstet Gynecol Scand. 2016:95(12):1368-75.

3. Luke B, Brown MB. Elevated risks of pregnancy complications and adverse outcomes with increasing maternal age. Hum Reprod. 2007;22(5):1264-72.

4. Ananth CV, Keyes KM, Wapner RJ. Pre-eclampsia rates in the United States, 1980-2010: age-period-cohort analysis. BMJ. 2013;347:f6564.

5. Smulian JC, Ananth CV, Kinzler WL, Kontopoulos E, Vintzileos AM. Twin deliveries in the United States over three decades: an age-period-cohort analysis. Obstet Gynecol. 2004;104(2):278-85.

6. Ananth CV, Misra DP, Demissie K, Smulian JC. Rates of preterm delivery among Black women and White women in the United States over two decades: an age-period-cohort analysis. Am J Epidemiol. 2001;154(7):657-65.

7. Klemetti R, Gissler M, Sainio S, Hemminki E. Associations of maternal age with maternity care use and birth outcomes in primiparous women: a comparison of results in 1991 and 2008 in Finland. BJOG. 2014;121(3):356-62.

8. Wang J, Sauer MV. In vitro fertilization (IVF): a review of 3 decades of clinical innovation and technological advancement. Ther Clin Risk Manag. 2006;2(4): 355-64.

9. Alexander GR, Himes JH, Kaufman RB, Mor J, Kogan M. A United States national reference for fetal growth. Obstet Gynecol. 1996;87(2):163-8.

10. Yang Y, Schulhofer-Wohl S, Fu WJ, Land KC. The intrinsic estimator for ageperiod-cohort analysis: what it is and how to use it. AJS. 2008;113(6):1697-736.

11. Ananth CV, Vintzileos AM. Trends in cesarean delivery at preterm gestation and association with perinatal mortality. Am J Obstet Gynecol. 2011;204(6): 505 e1-8. 
12. Lavery JA, Friedman AM, Keyes KM, Wright JD, Ananth CV. Gestational diabetes in the United States: temporal changes in prevalence rates between 1979 and 2010. BJOG. 2017;124(5):804-13.

13. Morris JM, Totterdell J, Bin YS, Ford JB, Roberts CL. Contribution of maternal age, medical and obstetric history to maternal and perinatal morbidity/ mortality for women aged 35 or older. Aust N Z J Obstet Gynaecol. 2017;58:91

14. Ananth CV, Balasubramanian B, Demissie K, Kinzler WL. Small-for-gestationalage births in the United States: an age-period-cohort analysis. Epidemiology. 2004;15(1):28-35.

15. Margerison-Zilko $C$. The contribution of maternal birth cohort to term small for gestational age in the United States 1989-2010: an age, period, and cohort analysis. Paediatr Perinat Epidemiol. 2014;28(4):312-21.

16. Rolnik DL, Wright D, Poon LC, O'Gorman N, Syngelaki A, de Paco MC, et al. Aspirin versus placebo in pregnancies at high risk for preterm preeclampsia. N Engl J Med. 2017;377(7):613-22

17. Schaap TP, van den Akker T, Zwart JJ, van Roosmalen J, Bloemenkamp KWM. A national surveillance approach to monitor incidence of eclampsia: The Netherlands Obstetric Surveillance System. Acta Obstet Gynecol Scand. 2019;98(3):342-50.

18. Knight M. Ukoss. Eclampsia in the United Kingdom 2005. BJOG. 2007;114(9): 1072-8.

\section{Publisher's Note}

Springer Nature remains neutral with regard to jurisdictional claims in published maps and institutional affiliations.

Ready to submit your research? Choose BMC and benefit from:

- fast, convenient online submission

- thorough peer review by experienced researchers in your field

- rapid publication on acceptance

- support for research data, including large and complex data types

- gold Open Access which fosters wider collaboration and increased citations

- maximum visibility for your research: over $100 \mathrm{M}$ website views per year

At BMC, research is always in progress.

Learn more biomedcentral.com/submissions 